\section{Consenting to participate in research for the treatment of cancer: The patient's perspective}

\author{
By Lorna Butler
}

\section{Abstract}

The purpose of this study was to explore cancer patients' experiences with the process of consenting to participate in experimental, randomized design studies. A descriptive study using focus groups was conducted to gain a better understanding of how to improve and facilitate consent discussions between investigators and patients. Categories were defined using a deductive approach based on the literature and the Medical Research Council of Canada (MRC) framework for the consent process. The focus group sessions addressed the question of "Now that I have been through the clinical trial research process, what would I have liked to have known?". Implications for nursing practice and recommendations for defining the consent process from the participants' perspective are outlined.

\section{Introduction}

A research review board (RRB) within an institution functions to ensure that any research involving human subjects, either staff or patients, is scientifically valid and meets ethical requirements at all levels of the research design (Meslin, 1992; VGH, 1993). It has been suggested that RRBs spend more time on the detail of the actual consent form than on the consent process (Levin, 1988). What may be happening is that in its attempt to protect the right of human subjects to consent, the RRB requires evidence of ethical analysis. Ethical analysis must consider both the decision outcome and the decision-making process to achieve that outcome (Pellegrino, Siegler \& Singer, 1990). When this is not forthcoming, the RRB may become, by default, the educational body for teaching investigators the difference between the consent form and the consent process.

Over two years, the research review committee (RRC) at a 650-bed tertiary care teaching hospital reviewed approximately 290 research protocols and consent forms. In one 10-month period alone, 293 "administrative actions" or letters to investigators resulted from the reviews (Medical Staff Office, personal communication, July 1993). The vast majority of the letters were about deficiencies or problems with the proposed consent forms or consent process. Problems included readability of the forms due to overly complex language, the format and structure of the forms not always well distinguished, and forms missing

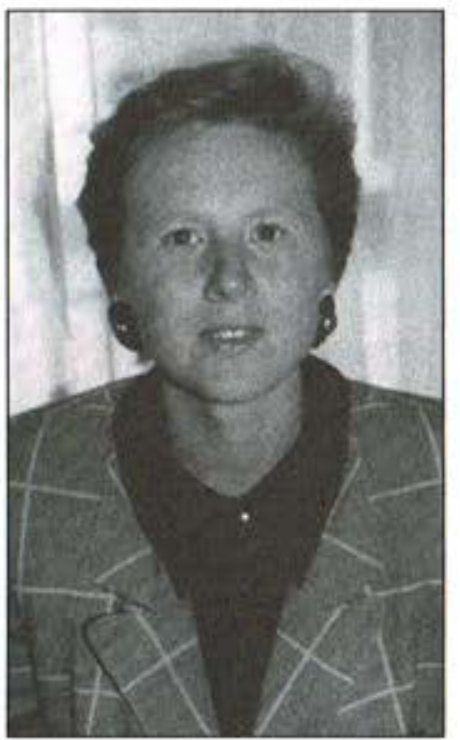

Lorna Butler elements required by the RRC in terms of content material.

The experience of this research review committee in dealing with consent issues, as described above, indicated that the research community did not have a uniform understanding of consent requirements. The existence of such discrepancies has the potential to adversely affect the effectiveness and efficiency of the consent process with patients who are approached for research. However, data or patient feedback to verify or disprove this assertion with the study hospital was not available.

\section{Review of the literature}

The practice of medicine and the provision of health care are grounded in recommendations by scientific data derived from individual participation in research studies. Informed consent is not a singular event but a complex process which involves recognition of individual values and beliefs, information exchange and decision-making between physician-patient and/or research investigator-potential participant. Canadian case laws have outlined the legal requirements for research consent (Halushka v. University of Saskatchewan, (1965), 53 D.L.R. (2nd) 436 Sask. C.A.); Weiss v. Solomon, (1989), 48 CCLT 280 (Que. S.C.). As well, documents such as the Declaration of Helsinki and the Medical Research Council Guidelines on Research Involving Human Subjects, 1987, describe the ethical/legal elements of the consent process. The disclosure requirements are stringent and the scope of elements which must be included is broad. To what extent investigators impart reasonable information to the participant for making an informed choice to enter such studies is uncertain and raises issues of paternalistic decision-making.

Schools of health professions, where the graduating students become the clinical investigators within today's hospitals and universities, are varied in the provision of education on bioethical issues and the practice of ethical analysis (Pellagrino, Siegler and Singer, 1990). It is only within the last three decades that the health care system has recognized ethical analysis as a component of the educational curriculum for health professionals (Pellegrino et al., 1990). Texts and journal publications on the topic are available to the research

\section{ABRÉGÉ}

\section{CONSENTEMENT POUR PARTICIPER À UNE RECHERCHE SUR LE TRAITEMENT DU CANCER: LA PERSPECTIVE DU PATIENT}

La présente étude avait pour but d'explorer l'expérience vécue par les patients au niveau du processus de consentement pour participer à des études aléatoires et expérimentales. On a mis sur pied une étude descriptive à l'aide de groupes de réflexion afin de mieux comprendre comment on pouvait améliorer et faciliter les discussions portant sur le consentement entre les investigateurs et les patients. La définition des catégories est le résultat d'une approche déductive basée sur les écrits et sur les principes directeurs du Conseil de recherches médicales du Canada (CRMC) en matière de consentement. Lors des sessions, les groupes de réflexion se sont penchés sur la question suivante: "Maintenant que j'ai vécu l'expérience de recherche dans le cadre d'essais cliniques, qu'est-ce que j'aurais aimé savoir avant de commencer?". L'étude souligne les répercussions pour la pratique infirmière et les recommandations visant à définir le processus de consentement du point de vue des patients.

Lorna Butler, RN, PhD, is a clinical scientist in nursing research at the Queen Elizabeth II Health Sciences Centre, Halifax, Nova Scotia. 
community (Levine, 1986; Rozovsky, 1990; Hoffmaster, 1989; Bohaychuk and Ball, 1993). Goldman \& Katz (1985) cite two core components which investigators must be skilled in achieving: 1) providing comprehensive explanations for individuals and 2) providing opportunity for questions such that the investigator can determine if the individual has an appreciation and knowledge of the information that was provided.

It is not clear if the technical requirements of these two core components are transferred into actual research practice in a way which is comprehensive, yet simple enough for all participants in the process to understand. A literature review has not found information available in layman's terms to assist both the researcher and the patient to communicate comfortably and clearly about participation in research. Nor was published information found about the patients' experiences in and expectations of the research consent process.

\section{Purpose and research questions}

The purpose of this study was to explore patients' experiences with the process of consenting to participate in clinical research studies. The specific research questions included:

1. What do participants describe as the consent process that was involved in their decision to enter a research study?

2. What information do participants perceive is necessary to make a decision to participate?

3. Is there a difference between the information patients used in deciding to participate at the time, and their own retrospective opinion of what they would have liked to have known when making the decision?

4. If patients perceive a personal risk in consenting to participate, what kind of further information do they consider necessary in order to make the decision?

\section{Figure One: Principles of consent: Competent participants Medical Research Council of Canada}

\begin{tabular}{|c|c|c|c|c|c|c|}
\hline \multirow{13}{*}{$\begin{array}{l}\text { Involvement } \\
\text { is voluntary }\end{array}$} & \multirow{13}{*}{$\begin{array}{c}\begin{array}{c}\text { Freedom } \\
\text { from } \\
\text { undue } \\
\text { influence }\end{array} \\
\text { Freedom } \\
\text { from } \\
\text { any } \\
\text { pressure }\end{array}$} & \multirow{13}{*}{$\begin{array}{c}\text { Receipt of } \\
\text { information } \\
\text { language } \\
\text { they } \\
\text { understand } \\
\text { enough } \\
\text { information } \\
\text { of study }\end{array}$} & \multirow{13}{*}{$\begin{array}{l}\text { Information } \\
\text { must } \\
\text { include } \\
\text { a) the reason for thestudy } \\
\text { b) research techniques } \\
\text { c) the reason why the } \\
\text { prospective subject is be- } \\
\text { ing invited to take part } \\
\text { d) the reasonably } \\
\text { anticipated benefits } \\
\text { and consequences of } \\
\text { the study itself } \\
\text { e) the reasonably } \\
\text { anticipated benefits } \\
\text { and consequences of } \\
\text { the study for the } \\
\text { prospective subject } \\
\text { and society (if none, } \\
\text { this should be stated) } \\
\text { f) the foreseeable } \\
\text { risks, including } \\
\text { discomforts and } \\
\text { inconveniences, to the } \\
\text { prospective subject } \\
\text { g) the foreseeable } \\
\text { risks of the study itself } \\
\text { h) complete details re- } \\
\text { garding confidentiality } \\
\text { of prospective subjects } \\
\text { i) the anticipated time } \\
\text { commitment for subjects } \\
\text { j) the intent to conduct a } \\
\text { follow-upstudy inthe fu- } \\
\text { ture and the retention of } \\
\text { data } \\
\text { k) the rules for stopping } \\
\text { the study and withdraw- } \\
\text { ing the subject and } \\
\text { l) the right of the subject } \\
\text { to withdraw from the } \\
\text { study at any time and } \\
\text { without penalty }\end{array}$} & \multirow{13}{*}{$\begin{array}{l}\text { Additional } \\
\text { information if direct } \\
\text { care is affected } \\
\text { a) the patient's } \\
\text { prognosis without } \\
\text { intervention } \\
\text { b) alternative } \\
\text { interventions } \\
\text { available } \\
\text { c) experimental } \\
\text { aspects of } \\
\text { interventions } \\
\text { proposed } \\
\text { d) interventions to } \\
\text { be unavailable to a } \\
\text { patient who } \\
\text { becomes a subject, } \\
\text { for the sake of the } \\
\text { research } \\
\text { e) an estimate of the } \\
\text { likely success and } \\
\text { failure of all the } \\
\text { interventions which } \\
\text { may be offered and } \\
\text { withheld } \\
\text { f) an estimate of the } \\
\text { risks and possible } \\
\text { adverse effects of } \\
\text { interventions } \\
\text { offered; and } \\
\text { g) a clear distinction } \\
\text { between procedures } \\
\text { in the research } \\
\text { protocol and those } \\
\text { that would be part of } \\
\text { usual patient care }\end{array}$} & \multirow{13}{*}{$\begin{array}{c}\text { Consent } \\
\text { form signed } \\
\text { Commence }\end{array}$} & \multirow{13}{*}{$\begin{array}{l}\text { Ongoing } \\
\text { dialogue } \\
\text { and } \\
\text { provision of } \\
\text { information }\end{array}$} \\
\hline & & & & & & \\
\hline & & & & & & \\
\hline & & & & & & \\
\hline & & & & & & \\
\hline & & & & & & \\
\hline & & & & & & \\
\hline & & & & & & \\
\hline & & & & & & \\
\hline & & & & & & \\
\hline & & & & & & \\
\hline & & & & & & \\
\hline & & & & & & \\
\hline & & & & & & \\
\hline
\end{tabular}

Continuous process of education throughout research 


\section{Method}

To understand how the consent process was conducted within the organization, individuals who experienced the process were asked to provide the data. A qualitative research method using focus groups was chosen to conduct the study. Focus groups provide an opportunity to observe interactions that reflect both attitudes and experiences of the participants (Morgan, 1988). This study used the approach of a clinical focus group to obtain data which would help explain individuals' unconscious motivation to consent to participate in a research study as part of their treatment (Morgan, 1988). The groups were used to 1) explore participants' experiences with consenting to participate in treatment-related research studies, 2) identify participants' expectations of the consent process and, 3) develop ideas and opportunities for improvement in the present process of achieving informed consent (Leebov \& Ersoz, 1989; Calder, 1977).

Preparation for the focus group sessions was based on the principles of consent for competent participants as defined by the Medical Research Council of Canada (1987). Consent was considered to be a continuous process of education throughout the research study (Figure One).

\section{Composition of focus groups}

Three distinct focus groups were proposed for the study. Criteria for structuring the groups was based on the anticipated degree of risk involved for the participants agrecing to enter a research study.

Group 1 was comprised of individuals who consented to participate in a randomized clinical trial study to evaluate two types of heparin therapy as a preventative intervention for the development of deep vein thrombosis (DVT) following colorectal surgery. The underlying pathology which led to the need for surgical intervention varied, however all who participated in the study had a diagnosis of colon cancer (Anderson \& Grant, 1993).

Group 2 was comprised of individuals who consented to participate in a three-year, randomized phase III drug trial study comparing the benefit of two drugs, levamisole, a chemotherapeutic agent and Bacillus Calmille-Guerin (BCG), a vaccine (Quirt, et al., 1991). All participants had a diagnosis of malignant melanoma which had been surgically resected.

Group 3 was comprised of women diagnosed with breast cancer who agreed to participate in a randomized clinical trial which tested the efficacy of administering chemotherapy immediately after surgery. This focus group was comprised of women who had lived with cancer for at least 10 years since the clinical trial (Bodurtha, Steele \& Bethune, 1983). Participants in the focus groups may or may not have experienced a relapse of their disease since the completion of the clinical trial.

\section{Barriers to accrual}

A total of 27 individuals were eligible to participate in the study and agreed upon telephone contact to attend one of the three groups. A total of seven individuals actually attended the three groups. Given the small number of participants, it was decided that a fourth focus group session should be conducted. Participants in the fourth group were diagnosed with lung cancer and consisted of individuals who had few signs and symptoms suggestive of metastatic disease (Bethune, 1994). Five individuals were contacted and agreed to participate. Only two actually attended the focus group.

\section{Study sample}

The sample consisted of five females and four males between the ages of 52 and $73(\mathrm{~m}=64)$. All had participated in treatment-related clinical trial research during the treatment of their cancer. Four participants had breast cancer, one had melanoma, two had lung cancer and two had colon cancer.

Six participants had either attended or completed high school, two had secondary education and two had university degrees. Six participants had experience in more than one research study. In addition to the clinical trials research study (CTRS) used as the basis for accrual to this study, three individuals had agreed to have physical examinations for research purposes, two had testing procedures (i.e. x-ray), three had participated in structured interviews, one had completed research questionnaires, two had attended group meetings and one had been part of a telephone survey. Only three participants had no additional research experiences prior to their treatment-related CTRS for cancer.

All participants initially received a letter of introduction to the study from the physician investigator of the CTRS. A follow-up phone call was then made from the physician's office asking if they were interested in learning more about the study and, if so, permission to release their name to the study investigators who would explain the study. The researcher contacted all potential participants to explain the study and arrange the focus groups. Participants were informed that only one session would be held, that other individuals who had been part of the same CTRS would be in the group, their identity would be protected by the researchers and that the physician-investigator would not know who attended the session. Access to health records was not requested. Participants were asked not to record their name or any other identifying information on the forms used in the focus group. They were also informed that all data would be coded and reported as grouped data. A written consent form approved by the hospital research and review committee was used.

\section{Data collection}

Three of the four focus group meetings used the same format. The purpose of the focus group was explained by one of the investigators as a discussion to share thoughts and experiences on agreeing to participate in a research study. Participants were asked to specifically discuss how they were able to make their decision to be part of a study and agree to sign the consent form. The two study investigators were present throughout the focus group sessions. One investigator acted in the role of facilitator for the focus group discussion and the other participated as an observer, recording the group interactions and discussions. A third person was available to record the discussion and key points on the flip charts.

To begin the session, a pre-discussion questionnaire was used to help participants start to think about what informed consent may mean to them. Questions were both forced choice and open-ended. Sample questions included: "What do you believe should be included in asking patients to participate in a research study as part of their treatment?" "When you agreed to participate in the research study as part of your treatment, what did you need to know to help you decide to consent to be part of the study?", and "Given your previous experience with consenting to participate in a research study, what does informed consent mean to you?". Participants were asked to share their responses to the pre-discussion questionnaire to begin the discussions. Discussions were not limited to the pre-discussion guide, but were unstructured and based on the participants' experiences.

Data from the focus group sessions were obtained by flip chart recording of participants' thoughts, ideas and suggestions. Participants were then given a hand-out about consenting to be part of a research study at the hospital: "Discussion Guide for Patients and Care Givers" and asked if such a document would have been useful in helping them to decide about consenting to treatment. Responses and discussions about such an aid were also recorded on the flip charts. The results of this aspect of the study will be reported elsewhere. Only one individual attended Focus Group 3. A one-to-one interview was conducted and the participant completed the study questionnaires. The data was included in the overall analysis, however no item ratings or frequencies of responses could be generated from group 3 data.

\section{Data analysis}

Responses to the pre-discussion questionnaire were analyzed using descriptive statistics of frequency of responses and percentages. The flip chart and observer notes were transcribed following each session and the item ratings were ranked in order of frequency of responses. The transcribed data from the flipcharts was analyzed using manifest content analysis. Themes within the data were identified as the unit of analysis. Categorical schemes were developed using a deductive approach based on the presenting literature and the MRC framework of the informed consent process (1987) (see Figure One). 


\section{Results}

Pre-discussion questionnaire. For the majority of participants, informed consent meant that they would understand what was involved in a study and the reason for doing the study $(44 \%, n=4)$ or that they had been told all that they needed to know to participate $(22 \%, \mathrm{n}=2)$. Only one individual believed informed consent meant signing a form. When asking patients to participate in a research study as part of their treatment, most responded that as much information as possible should be provided $(48 \%, n=4)$ and time provided to understand and consider what was happening $(22 \%, n=2)$ was critical.

When asked about who they believed should explain the research study to patients, 33 per cent responded that the actual researcher was responsible. Twenty-two per cent believed all members of the health team were responsible to provide information. In their own experience, most had received their information from the attending physician who may or may not have been the researcher. The participants were then asked the question: "When you agreed to participate in the research study as part of your treatment, what did you need to know to help you decide to consent to be part of the study?". Most left this question unanswered but wrote the following comments: "At that time I didn't need to know anything. I'm better informed now and would ask questions about long-term effects"; "I didn't have to know anything except that it could help me"; and "Not too much, having just been diagnosed with lung cancer. I guess I didn't really think of much else".

The final question on the pre-discussion questionnaire identified all the components of a consent form required by the RRC of the study hospital. Most individuals had received information on the purpose of the study, why the study was being done and why they were asked to participate. Half had been given an explanation about what was involved in the study, the risks and the benefit to others. Twenty-two per cent or less received information on benefit to self, alternative treatment if not in the study, voluntary participation, confidentiality and the use of the data at completion of the study, such as how information would be presented at conferences or in publications.

Focus group interactions. Using content analysis, six categories emerged from the narrative data recorded on the flip charts and from the observer's notes. Table One describes the frequency of responses in each of the identified categories (see Table One). Inter-rater reliability testing was conducted to determine per cent agreement in using the defined categories for coding of the data. Initial reliability was low $(82 \%)$. The definitions were further refined and $92 \%$ agreement was achieved between the raters. The categories which emerged include maintaining the process of consent, confidence in the messenger, right to decide, making sure of what I heard, frontiers of knowledge: burden or benefit, and what I expected to occur. Maintaining the process of consent. This category refers to a number of activities initiated by the researcher that maintained informed consent throughout the study. This included identifying who provides information, meeting the investigator, signing and receipt of consent forms and continuing communication throughout the study. Ongoing, helpful information was described most frequently. Statements which described this category were: "Always felt I was told the truth so long as first-hand, not second or third"; "After signing consent, nurses were very helpful in getting answers to questions" and "Doctor was nice but didn't tell much". Issues related to the signing of the consents were also key components. Participants commented about remembering the signing of the consent

form but were unable to remember what it looked like or the content information. Such statements included: "Didn't ask anything and wasn't told anything" (re signing); "Understood what would take place before signing consent form" and "Blurred as to what was consent for research and consent for treatment". This category was referenced most often in the study (see Table Two).

Confidence in the messenger. The category entitled confidence in the messenger refers to the investigator-patient relationship and was identified by the experience of the individual in the decision-making process. This category was characterized by a paternalistic approach used by investigators in the consent process. Most of the participants reported that they were very confident in the researcher and in participating in research as part of their treatment. Questioning the investigator did not seem to be a key factor for these individuals. Responses related to trusting the investigator's decision such as: "Whatever the doctor said was OK"; "I would have signed my life away. Thought never entered my head not to do what they suggested"; "I'd have jumped out the window at that point if doctor told me to" and "I just asked Dr. B. if he thought it was a good idea and he said sure, so I didn't ask any more or cared what they did".

On the other hand, a certain degree of vulnerability was present in the decision to relinquish control to the physician for decisions. These comments included: "Didn't care, just wanted treatment"; "Sometimes feel stupid to ask questions and shouldn't"; "Timing and place for interview not very private... you might be reluctant to ask questions and talk. Just drawing the curtains doesn't block the sound".

Right to decide. This category was defined as an individual's beliefs about personal responsibility for their own health, which influenced their role in requesting the necessary information. The participants made reference to those activities they initiated to obtain information for entry into the study and their ability to also withdraw from the study. Information strategies used by the participants included calls to the investigators' offices to find out results of tests conducted as part of the study and including their spouse in the discussions to assist them in asking questions regarding the treatment events and study procedures. All participants agreed that they had found it difficult to ask questions because they didn't know what to ask. This was especially difficult when the decision to participate in a study was a new experience.

Making sure of what I heard. References for this category were characterized by the situational context of volunteering to participate in research. Participants referred to the time allotted for reflecting on

Table One: Frequency and per cent of responses by thematic categories $(n=9)$

Themes

Maintaining the process of consent

What I expected to occur

Confidence in the messenger

Making sense of what I heard

Frontiers of knowledge - burden or benefit

The right to decide

Other

Frequency of response

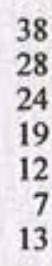

TOTAL

$\begin{array}{ll}141 & 100.0\end{array}$

Percentage of response (\%)

$38 \quad 26.9$

$\begin{array}{ll}28 & 19.8\end{array}$

17.1

$19 \quad 13.5$

$12 \quad 8.5$

7
13.9

$\begin{array}{lr}3 & 9.3\end{array}$

Table Two: Type of responses in category "maintaining the process of consent" by frequency and per cent $(n=9)$

\section{Type of responses}

Satisfied with the study Signing the consent form Who explained study

Family involvement

Time provided prior to signing consent Satisfied with the study

TOTAL
Frequency of response

12

11

8

4

2

1

38
Percentage of response ( $\%$ )

31.6

28.9

21.0

10.5

5.2

2.6

$100 \%$ 
the explanation as it related to their personal situation and the time one could take to make his or her decision to enter the CTRS. The overriding issue in this category was time. Time was considered from the perspective of the time patients are approached for study accrual and the time allowed for them to process the information provided to make their decision. The following excerpts identify the variation in respondents' perspectives on time: "I was approached to be part of the study before surgery. I was really upset about my condition - felt it wasn't the best time, but likely would have agreed anyway - so timing of the request probably didn't make much difference". Another individual within the group responded that... "When the study team came in prior to the operation, you don't focus on much else except that you have colon cancer and you won't know what's going to happen until you're in the OR, so your attention isn't on research dye tests you don't recall the details". Others in the group believed that "... it didn't make any difference if there was time to read or think as opposed to signing the consent form right away".

Frontiers of knowledge: Burden or benefit. This category refers to the process an individual uses to decide between the good of society and personal gain to agree to participate in research. It was a sense of doing what is best to generate new knowledge in the face of uncertainty. The majority of responses were focused on personal gain and not the good of society. Individual's responses reflected the following beliefs: "Not sure how I would answer if I were told the study may not benefit me. Participated in study to help others and myself. Might learn more about me"; "Only needed to know study wouldn't harm. Could only help me at the time" and "Would ask purpose of study. How will it affect me? What information would you gain by the study?".

What I expected to occur. This category refers to the perceived expectation of the participants to engage in the CTRS and their actual experience from accrual to closure of the study and to dissemination of results to the participants. Interestingly, most participants talked about the end results of the research and a desire to know how they contributed to the outcome (29\%). "Would like to know what part I would be playing in study. Would I get any results"; "Like to be told what was accomplished when study was over. Like to know ending" and "Interested in what were the results of the study - did chemotherapy make a difference or not?"

A second area of concern was the explanation of procedures (25\%). Participants were not able to distinguish between what was the usual care and what procedures were specifically related to the CTRS. "Imagination running while waiting. No specifics. Understood dye test but unsure of involvement to have the test. Idea of more needles and stretchers and I was delayed which was quite upsetting."

Other. There were some issues that did not fit under the defined categories, which were termed "other". Items in this category were identified by a specific focus group but were not consistently reported across the groups. Three issues did emerge. The first referred to uncertainty of information about the conduct of the study. Data related to "Waiting for bone scan results took two weeks - that was the worst thing" and "Called by the doctor's office re: chemotherapy, yet family doctor did not know about it. The specialist assumed the family doctor would do the chemotherapy without letting them know". The second issue was about their knowledge of the health care system. Results indicated that participants may respond differently when asked to participate in a study if they have had prior research experience. "A little more informed now about hospitals so now might know what questions to ask". The third issue reflected participants' attitude toward research. Responses varied from: "Easy to walk into a study without knowing anything" to "Research work is interesting".

\section{What one should know to consent to participate in research}

At the completion of the focus groups, the participants were asked to review all the issues that had been written on the flipcharts from the discussion. The question was posed - "If you were asked to participate in a research study again, what do you believe, from the data presented, are the three priority issues individuals should know to agree to consent to a research study as part of their treatment?" Two key issues were consistently rated: 1) the need for more information about a study when asked to participate to facilitate patients' questioning and 2) a sense of trust in the physician to do what is right when an individual has no past experience or knowledge to support decision-making.

\section{Implications for nursing}

Based on the data generated from the focus groups, a number of implications for oncology nursing practice are identified. Patients with cancer who are asked to participate in a CTRS as part of their treatment feel very dependent on the attending physician, (whether the physician is the investigator or not), to facilitate decision-making for entry into a study. This dependency role appears to reflect the traditional paternalistic approach generated by the medical model, however the constraints imposed by the treatment system within an institution may in reality be the root cause of individuals' reliance on others.

The results indicated that from the participants' perspectives, potential candidates for accrual into a CTRS are approached at a time when the fear of cancer and one's prognosis is the main consideration, not a research study. Patients perceived that they had very little time to decide and depended on the health professional, mainly the attending physician, to help them understand what was happening. Guidance was needed in making a choice between usual treatment and treatment as part of a CTRS. This finding highlights the need to emphasize the difference between consent by obtaining one's signature on a consent form and the process of consent which is the continuing exchange of information between the research staff and the participant throughout the study (MRC, 1987). Nurses hired as clinical research associates/study coordinators play a key role in the provision of information prior to obtaining a signature for consent. Assessing a potential participant's readiness to consent to a CTRS and ensuring that all questions are answered to the participant's satisfaction should be the responsibility of the nurse. Nurses are most often the person directly involved in explaining the study for accrual purposes. It is frequently the nurse who also maintains ongoing contact with study participants for data collection purposes throughout a study. Providing explanations and information about their involvement in the study could be part of that ongoing dialogue. Participants may also feel more comfortable asking questions about a study to the nurse with whom they have been able to establish an ongoing relationship.

The lack of prior experience with research as a form of treatment was thought to contribute to patients' vulnerability to make "the right choice". Again, nurses as study coordinators can make a significant contribution in their capacity as educators for patients, but also for their nursing colleagues. Nurses in clinical practice are most often exposed to medical research and provide support to investigators and research teams (Butler, 1996). In order to meet the ethical obligations of informed consent by patients while supporting participant accrual, practising nurses must be knowledgeable about the CTRS and expectations of participants. Developing collegial relationships between nursing divisions in health care institutions and study coordinators hired by individual investigators is essential.

It was of interest to note that the degree of risk involved as a study participant did not contribute to these participants' decisions to participate in a CTRS. The intent in structuring the focus groups had been to identify potential risks by type of study, however, this was not an identified issue. This may have been due to the patients' lack of confidence to ask questions prior to consenting to participate. However, one participant did refuse a particular invasive procedure once he was in the testing department. He shared that he had no idea what the test was or what was involved, although he had signed the study consent.

These data clearly presented the need for nurses to advocate on behalf of the patient and to play a more active role in ensuring family involvement in the consent process. This will help to facilitate questioning and provide opportunity for more than one person to hear the messtge. Family members can then help each other to understand what was heard. For nurses who work as study coordinators, the timing and delivery of information is crucial to patients' understanding of the CTRS.

Nurses are in a key role to influence the process of informed consent in the clinical practice setting. Participants in this study did not actually make an independent decision to enter a CTRS but relied on direction from others they trusted. The experiences of fear and uncertainty 
throughout the actual study heightened an awareness of the need for careful explanation about CTRS. It was of interest to note that three individuals made reference to uncertainty related to referral of their treatment to community agencies rather than continuing to attend the cancer clinic. The discomfort experienced by not knowing the ability of the community agency to administer their care could be alleviated by a managed care approach and nurse-to-nurse consultations between centres. Again, the need to maintain the process of informed choice over time was identified. Nurses are well positioned to do this.

Explaining the rationale for what is happening and assisting patients to distinguish between usual care and what is a component of actual research is important. More attention is also required around preparing patients for study closure. All participants felt they had "just ended" and were left not knowing if their role as a research participant was beneficial to their care. They were also unsure if they had helped to make a contribution to improving cancer care. Health professionals need to recognize the significance of the individual contribution each participant makes to a CTRS. The benefit of receiving a particular treatment may not be the only potential gain a person wishes to achieve when participating in a CTRS.

\section{Further research}

The reasons why patients agree to participate in clinical trials research as part of their treatment are complex (Shain, 1994). This study was comprised of a small group of middle-aged Caucasians treated at the same study site. A more diverse group using a multi-centered approach with different age ranges, cultural backgrounds, and the inclusion of family members would provide for a broader representation of experiences. Participants in this study had agreed to a CTRS as a first line of treatment. How the decision-making process might differ between patients who have experienced a first treatment for cancer, as compared to those who had failed to respond to a treatment protocol or those who experience a recurrence, requires further study.

The analysis provides a descriptive view of patients' experiences in deciding to participate in a CTRS as their treatment for cancer. There is a need to further study each of the thematic areas and the individual units of analysis in a large scale to validate the categories constructed. Items in the "other" category such as uncertainty of information and procedures followed require further exploration for their significance in influencing the consent to future studies.

\section{References}

Anderson, D. \& Grant, B. (1993). A study to compare the effectiveness of standard heparin to low molecular weight heparin in patients undergoing colorectal operations. Study in progress.

Bethune, D. (1994). A randomized trial of alternate strategies for investigating patients with assumed operable lung cancer. (Surgical Clinical Trial Study).

Bodurtha, A., Bethune, B. \& Steele, B. (1983). Immediate vs. delayed adjuvant chemotherapy in a patient with operable breast cancer. Unpublished raw data.

Bohaychuk, W. \& Ball, G. (1993) Standard Operating Procedures for Investigators (2nd ed.), Good Clinical Research Practices: Hampshire, UK.

Butler, L. (1995). Valuing research in clinical practice: A basis for developing a strategic plan for nursing research. Canadian Journal of Nursing Research, 27(4), 33-49.

Degner, L. \& Sloan, J. (1992). Decision-making during serious illness: What role do patients really want to play? Journal of Clinical Epidemiology, 45, 941-950.

Goldman, J. \& Katz, M. (1982). Inconsistency and institutional review boards. Journal of American Medical Association, 248(2), 197-202.

Hoffmaster, B. (1990). The Medical Research Council's New Guidelines on Research Involving Human Subjects: Too Much Law, Too Little Ethics. Health Law in Canada, 10(1), 146-155.

Leebov, W. \& Ersoz, C. (1991). The health care manager's guide to continuous quality improvement. American Hospital Association.

\section{Conclusion}

While there is existing literature which addresses barriers to patients agreeing to participate in a CTRS, no data were found that specifically examined patients' experiences or beliefs about what an individual should know prior to agreeing to participate in research. A key issue identified by the participants was the dependency on health professionals to make the "right choice" in agreeing to enter a CTRS as part of their treatment. While there is a growing body of knowledge around patients' desire for information and participation in decision-making, the significance of this study's findings indicate that dependency appeared to be related to a lack of information rendering individuals vulnerable to make a decision(Degner \& Sloan, 1992). Nurses can directly influence this constraint by developing strategies to actively involve the patient and family in a process of informed consent. Recognizing one's personal beliefs about research and spending time exploring patients' concems is critical. Providing information to support understanding of the purpose for conducting a study needs to be facilitated by both the study coordinator involved in participant accrual and nurses providing the direct care. A description of the individual's involvement in the study beyond their usual care is necessary.

The role of the nurse was identified as twofold: that of an educator and advocate. Such roles included the patient's and family's continued understanding of the conduct of the research, their involvement as study participants, providing for support for patients to make informed choices and providing an environment where individuals felt comfortable to discuss their role as research participants, which could include withdrawing from a study.

While participants did not elaborate on the various roles of research team members or health professionals involved in their direct care, little attention was focused on nurses as the study coordinator or in providing direct care. There is a need to articulate the role of nurses who provide direct support to patients and families as study coordinators both within the institution and where research is conducted and specifically within nursing divisions where no direct professional linkages exist.

\section{Acknowledgements}

The author wishes to thank Anu MacIntos h for her support and participation in developing the initial research proposal and conducting the focus groups. The support provided by Colleen Clattenburg in the preparation and typing of this mamuscript is also acknowledged.

Levine, R. (1986). The Ethics and Regulation of Clinical Research (2nd ed.), Baltimore: Urban \& Schwarzenberg.

Medical Research Council of Canada. (1987). Guidelines on Research Involving Human Subjects. Ottawa: Author.

Meslin, E. (1993). Ethical issues in the substantive and procedural aspects of research ethics review. Health Law in Canada, 13(3), 179-191.

Morgan, D. (1988). Focus Groups as Qualitative Research. Newbury Park: Sage Publishers.

Pellagrino, E., Siegler, M. \& Singer, P. (1990). Teaching clinical ethics. The Journal of Clinical Ethics, 1(3), 175-180.

Quirt, I., Shelly, W., Pater, J., Bodurtha, A., McCulloch, P., McPherson, T., Paterson, A., Prentice, R., Silver, H., Willan, A., Wilson, K. \& Zee, B. (1991). Improved survival in patients with poor-prognosis malignant melanoma treated with adjuvant levamisole: A phase III study by the National Cancer Institute of Canada clinical trials group. Journal of Clinical Oncology, 9(5), 729-735.

Rozovsky, L., \& Rozovsky, F. (1990). The Canadian Law of Consent to Treatment. Markham: Butterworths Canada Ltd.

Shain, W. (1994). Barriers to clinical trials part II: Knowledge and attitudes of potential participants. Cancer Supplement, 74(9), 2666-2671.

Victoria General Hospital. (1994). Guidelines for Submission of Research Proposals. Halifax: Author. 